\author{
RESEARCH ARTICLE \\ 10.1029/2019JC015756 \\ Key Points: \\ - In situ and satellite observations \\ reveal different spatial patterns of \\ sea ice thickness (SIT) in Hudson \\ Bay between winter 2017 and 2018 \\ - Differences of up to $0.5 \mathrm{~m}$ in eastern \\ and southern Hudson Bay SITs are \\ attributed to variability in wind \\ driven ice dynamics \\ - Enhanced NW winds in winter \\ increase SIT in eastern Hudson Bay, \\ delaying spring breakup by 3- \\ 4 weeks and delaying navigation in \\ summer
}

Correspondence to:

S. Kirillov,

sergei.kirillov@umanitoba.ca

Citation:

Kirillov, S., Babb, D., Dmitrenko, I., Landy, J., Lukovich, J., Ehn, J., et al. (2020). Atmospheric forcing drives the winter sea ice thickness asymmetry of Hudson Bay. Journal of Geophysical Research: Oceans, 125, e2019JC015756. https://doi.org/10.1029/2019JC015756

Received 9 OCT 2019

Accepted 22 JAN 2020

Accepted article online 30 JAN 2020

(C)2020. American Geophysical Union. All Rights Reserved.

\section{Atmospheric Forcing Drives the Winter Sea Ice Thickness Asymmetry of Hudson Bay}

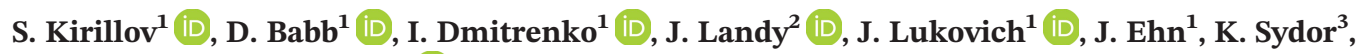 \\ D. Barber ${ }^{1}$, and J. Stroeve ${ }^{1,4}$ (D) \\ ${ }^{1}$ Centre for Earth Observation Science, University of Manitoba, Winnipeg, Manitoba, Canada, ${ }^{2}$ School of Geographical \\ Sciences, University of Bristol, Bristol, UK, ${ }^{3}$ Manitoba Hydro, Winnipeg, Manitoba, Canada, ${ }^{4}$ Centre for Polar Observation \\ and Modelling, University College London, London, UK
}

Abstract Recently, we highlighted the presence of a strong west-east asymmetry in sea ice thickness across Hudson Bay that is driven by cyclonic circulation. Building on this work, we use satellite altimetry and a unique set of in situ observations of ice thickness from three moored upward looking sonars to examine the role of atmospherically driven ice dynamics in producing contrasting regional ice thickness patterns. Ultimately, north-northwesterly winds coupled with numerous reversals during winter 2016/2017 led to thicker ice in southern Hudson Bay, while enhanced west-northwesterly winds during winter 2017/2018 led to thicker ice in eastern Hudson Bay that delayed breakup and onset of the summer shipping season to coastal communities. Extending the analysis over the 40-year satellite observation period, we find that these two different patterns of atmospheric forcing alter the timing of breakup by 30 days in eastern Hudson Bay and offer some skill in seasonal predictions of breakup.

Plain Language Summary The seasonal ice cover of Hudson Bay is characterized by a pronounced east-west asymmetry in ice thickness that is created by the regional pattern of ice drift.

However, this asymmetry varies from year to year. Using in situ and remotely sensed observations of ice thickness, we contrast the two winters of 2016/2017 and 2017/2018 and investigate the role of atmospheric forcing in creating this asymmetry by deforming and thickening the ice cover in certain regions of Hudson Bay. It was found that stronger westerly winds increase ice thickness in eastern Hudson Bay by up to $50 \mathrm{~cm}$ at the end of winter. This in turn delays the breakup of the ice cover in eastern Hudson Bay, allowing ice to persist longer into summer, delaying the start of the open water shipping season and the summer resupply to coastal communities.

\section{Introduction and Motivation}

Hudson Bay (HB) remains one of the least studied seasonally sea ice-covered regions of the Arctic due to a dearth of in situ observations, particularly during winter. This is in part attributed to perceived limits in economic potential and lack of infrastructure, as well as the fact that declines in sea ice in the central Arctic have been overall more dramatic. However, with 40 communities and various mine sites around the Bay that are only accessible by sea, as well as agricultural exports moving through the Port of Churchill, there is an established transportation network that has historically been confined by sea ice to the open water season (Andrews et al., 2016; Babb et al., 2019). Significant trends toward earlier breakup and later freeze-up of the ice cover (Andrews et al., 2018), coupled with increasing residential populations and mining activity, and the recent start of winter shipping to provide year-round access to mining ports has driven a considerable increase in shipping activity within HB over recent years (Babb et al., 2019). The economic and social importance of shipping within HB has encouraged previous work on changes in the timing of ice retreat and advance preconditioned by fall and spring air temperatures and winds (Hochheim \& Barber, 2014). With new available data sets on sea ice thicknesses (SITs) we focus here on the combined effect of sea ice thermodynamics and dynamics during the ice growth season in dictating the state of the end of winter ice thickness around HB that in turn impacts how the ice cover breaks up the following spring and, therefore, the length of the summer shipping season. Recent events have highlighted the need for such work as heavy ice conditions in eastern HB during summer 2015 and 2018 required the Canadian Coast Guard to escort resupply vessels through remnant sea ice and delayed resupply to these communities that had been inaccessible since the previous October. 
Previous studies have focused on sea ice concentration (SIC) and sea ice extent based on available data from airborne and satellite observations (Andrews et al., 2018; Cavalieri \& Parkinson, 2012; Danielson, 1971; Gagnon \& Gough, 2005; Galbraith \& Larouche, 2011; Hochheim \& Barber, 2010; Hochheim et al., 2011; Hochheim \& Barber, 2014; Kowal et al., 2017; Ogi et al., 2016; Stroeve et al., 2014; Tivy et al., 2011), whereas less is known about SIT across HB due to limited observations over an extended timeframe. Observations of SIT have historically been limited to manual drill hole measurements made on the landfast ice near nine communities through a partnership between the Canadian Ice Service (CIS) and local communities who utilize the ice for travel (Gagnon \& Gough, 2006; Gough et al., 2004; Markham, 1981). Based on this coastal data set, Markham (1981) and, later, Gagnon and Gough (2006) reported the maximum SIT ranged between 0.9 and $2.4 \mathrm{~m}$ with thinner ice observed in the southeast and thicker ice along the western coast of HB. However, beyond the landfast ice very little was known about SIT within the mobile ice pack until Landy et al. (2017) used ICESat and Cryosat-2 satellite altimetry data during winters 2003 to 2016 to present the first spatially complete observations of SIT in HB. Landy et al. (2017) found that approximately $1,000 \mathrm{~km}^{3}$ of sea ice forms annually in HB, a significant portion of which forms in the polynya in northwestern HB (Gunn, 2014; Saucier et al., 2004). But contrary to Markham (1981) and Gagnon and Gough (2006), the authors found the ice in northwestern HB to be on average $0.4 \mathrm{~m}$ thinner than ice in eastern HB. This east-west asymmetry in SIT across HB was found to be highly correlated (+0.69) with the vorticity of ice motion during winter as part of the cyclonic transport of sea ice around the Bay, in keeping with the correspondence between vorticity and SIC found by Hochheim et al. (2011) in an evaluation of springtime sea ice conditions in HB. Generally, sea ice is advected from northwestern HB, where a latent heat polynya forms under strong offshore winds and maintains thin ice throughout winter, to eastern HB, where the ice pack converges. Both Hochheim et al. (2011) and Landy et al. (2017) partly attributed the observed asymmetries to dynamical thickening of cyclonically drifting ice against the eastern coast, an effect first reported in Prinsenberg (1988) who suggested that ice ridging has to be accounted for within the seasonal ice volume in order to resolve the annual HB freshwater balance.

Despite the fact that zonal asymmetry of SIT is a distinct regional feature of HB (Landy et al., 2017), the impact of different atmospheric forcing conditions during ice growth (December-April) season on the interannual variability of dynamic and thermodynamic ice thicknesses and their influence on the ice retreat during summer remain unstudied. To address these gaps, we use the first in situ time series of SIT collected at three mooring locations in HB coupled with monthly fields of SIT from an extension to the database of Landy et al. (2017) to examine the seasonal development and end of winter anomalies in SIT across HB. Focusing on the two successive winters of 2016/2017 and 2017/2018 coinciding with mooring observations conducted as a part of BaySys project focused on the assessment of freshwater impact on physical, biological, and biogeochemical conditions in HB, we compare the role of thermodynamic ice growth and atmospherically driven sea ice dynamics on the state of the end of winter ice cover. In turn we relate these results to the different patterns of sea ice breakup during these two years when remnant seasonal sea ice persisted along the shores of southern and eastern HB, respectively.

\section{Data and Methods}

\subsection{Mooring and Reanalysis Data}

In this study we used SIT from three long-term oceanographic moorings deployed in western $\left(A N 01,59^{\circ} 58^{\prime}\right.$ $\mathrm{N}, 91^{\circ} 57^{\prime} \mathrm{W} ; \mathrm{NE03}, 57^{\circ} 50^{\prime} \mathrm{N}, 90^{\circ} 53^{\prime} \mathrm{W}$ ) and southeastern $\left(\mathrm{JBO}, 54^{\circ} 41^{\prime} \mathrm{N}, 80^{\circ} 11^{\prime} \mathrm{W}\right.$ ) HB (Figure 1a) from September 2016 to June 2018. Each mooring carried an upward looking five-beam acoustic Doppler current profiler (ADCP, Nortek Signature500), which in addition to currents measured the distance from the instrument to either the sea surface or the ice bottom when sea ice floes drifted over the profiler during the icecovered period. The 2- to 8-min bursts were transmitted at $2 \mathrm{~Hz}$ every 1-3 hr during two consecutive winters 2016/2017 and 2017/2018 (hereafter 2017 and 2018, respectively). The acoustic-derived ice drafts were first corrected for ADCP tilt, water level, and atmospheric pressure (Krishfield et al., 2014). They were then corrected for the speed of sound by applying a semiautomated method of open water detection based on spectral analysis of burst data and identifying the spectral maximums within the wind generated shortwave periods (3-8 s). Despite the reliability of this method, open water conditions were rarely observed during winter, introducing the largest error associated with sound speed due to the unknown seasonal and synoptic thermohaline changes in the surface layer. However, considering the shallow deployment depths of all 

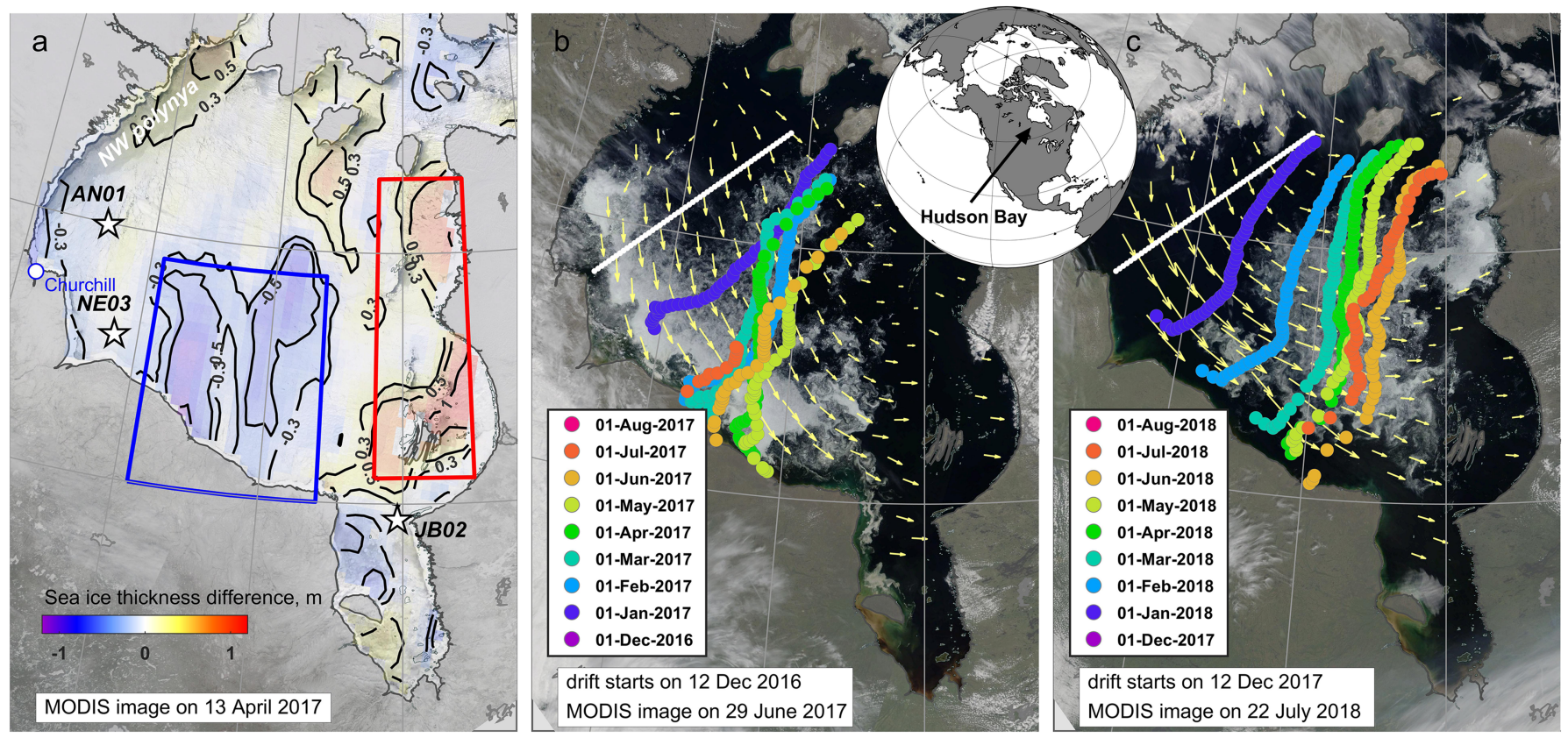

Figure 1. (a) The SIT difference between April 2018 and April 2017, as observed by CS2/SMOS, superimposed on a MODIS Terra image acquired on 13 April 2017, with the three mooring positions labeled. Two domains with the most pronounced SIT differences are enveloped with blue (southern domain) and red (eastern domain) rectangles. (b, c) The monthly projection of OSI SAF ice drift from the basic transect (white circles) during (b) winter 2017 and (c) winter 2018 . Ice projections are overlaid on MODIS images at the end of the melt season in each year. Yellow arrows show the mean OSI SAF ice drift vectors between 15 December and 15 April.

ADCPs (varying between 27 and $37 \mathrm{~m}$ ) and small variations of surface layer temperature and salinity during winter, we estimate the error from sound speed variations on ice drafts to be less than $0.05 \mathrm{~m}$. Within each burst outliers beyond $2.5 \sigma$, where $\sigma$ is the standard deviation of ice draft within the burst, were removed. Furthermore, only bursts with $\sigma<0.5 \mathrm{~m}$ and range $<1.0 \mathrm{~m}$ were used to determine a mean ice draft and calculate the mean ice thickness following Archimedes's principle. The densities of seawater and sea ice were taken as 1,024 and $930 \mathrm{~kg} / \mathrm{m}^{3}$, respectively, and a no-snowpack assumption was applied. Landy et al. (2017) showed that the mean maximum end of winter (April) snow depth in HB was only $0.15 \mathrm{~m}$, which, assuming a snow density of $300 \mathrm{~kg} / \mathrm{m}^{3}$, indicates a potential overestimation of SIT by only $0.05 \mathrm{~m}$. Though this value is likely much lower as typically less snow would have accumulated on thinner ice produced from December to March. Sea level pressures (SLPs) used for mooring data correction as well as surface wind speeds and air temperatures were taken from ERA-Interim reanalysis (Dee et al., 2011). Atmospheric reanalysis data were also used to estimate the ice thickness from thermodynamic snow-free growth as a function of cumulative freezing degree days (FDD, degrees Celsius) in a form of $h$ $(\mathrm{cm})=1.33 \times F D D^{0.58}$ (Lebedev, 1938). The thermodynamic ice growth was calculated individually for each mooring position, starting from the date that sea ice was first observed at the mooring location by either the ADCP or Moderate Resolution Imaging Spectroradiometer (MODIS) imagery, until the end of April, when the mean daily air temperatures become positive and the seasonal ice thickness reaches its maximum.

\subsection{Satellite Data}

The daily low resolution $(62.5 \mathrm{~km})$ sea ice drift product OSI-405-c of the EUMETSAT Ocean and Sea Ice Satellite Application Facility (OSI SAF) (Lavergne et al., 2010) is used to reconstruct the ice drift trajectories in the HB in 2017 and 2018. The empirical linear relationship between the ice drift and ERA-Interim wind speed (Figure 2) is used to fill-in the missing data in OSI-405-c data during May-July 2017 and April 2018 (Figure 3) when in situ SIC exceeds 15\%. This relationship is also applied within $100 \mathrm{~km}$ of the coast where satellite data for ice drift are not available. SIC was obtained from the daily 10-km OSI-409-a (1978-2015) and complementing OSI-430 (2015-2019) global ice concentration data set derived from passive 

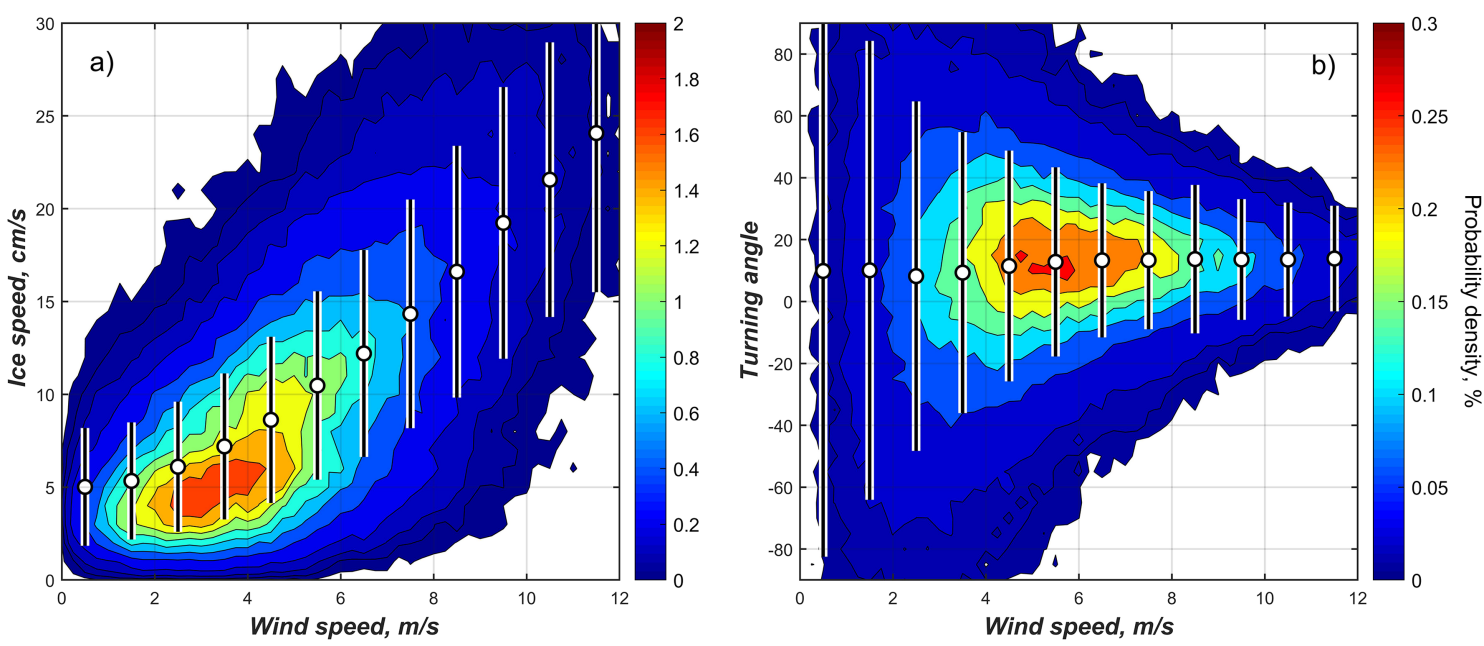

Figure 2. The PDF of correspondence between OSI SAF ice drift and 2-day-averaged ERA-Interim wind speeds and directions. The mean ice speed and directions are shown for every 1-m/s wind speed interval (white circles) along with their standard deviations (black lines). The least squares linear fit, which is shown with white line in (a), corresponds to the empirical model $\left(U_{\text {ice }}=0.0196 U_{\text {wind }}\right.$; and $12^{\circ}$ as a mean turning angle) used to restore the missing OSI SAF data.

microwave data (Special Sensor Microwave Imager and Special Sensor Microwave Imager Sounder). The breakup date in each grid cell was obtained by identifying the date when SIC dropped below $15 \%$ and remained below $15 \%$ for three consecutive days. The regional ice growth season was defined for each year from 1979 to 2018 as the period when SIC and surface air temperature over central $\mathrm{HB}\left(78-95^{\circ} \mathrm{W}, 55-63^{\circ}\right.$ N) were greater than $50 \%$ and below $0{ }^{\circ} \mathrm{C}$, respectively. Subsequently, the cumulative wind forcing and FDD over the central HB were calculated from reanalysis data for each ice growth season (Figure 4). To derive SITs in the entire HB in March-April 2017 and 2018, we utilize a combined Cryosat-2 and SMOS data product (CS2/SMOS), described in Landy et al. (2017), smoothed over a $5 \times 5$-node $(100 \times 100 \mathrm{~km})$ area. Weekly ice charts from the CIS provide a complimentary classification of the ice pack by partial concentration of different stages of development present at each mooring position throughout winters 2017 and 2018. Ice charts are derived from expert manual interpretation of Radarsat-2 imagery and other available aerial, remotely sensed and in situ observations (Fequet, 2005).

\section{Results and Discussion}

\subsection{The East-West Ice Thickness Asymmetry Derived From In Situ and Satellite Data}

The sea ice growth season of 2017 lasted from 15 December to 19 May and was 5 weeks shorter than the 2018 season (30 November to 6 June, see Table 1). The growth season in 2017 was associated with higher regional air temperatures, which led to lower FDD compared to 2018 (2605 vs. 3170, see Figure 4). As is typical of the $\mathrm{HB}$, freeze-up progressed from northwestern HB to the southeast during both winters (not shown). Ice thicknesses generally increased at all three moorings throughout both winters (Figure 3). However, this ice thickness increase demonstrates the spatial bias manifesting as a regional east-west asymmetry. This bias is well traced when comparing the measured ice thicknesses with the empirical (from FDD) thermodynamic growth of sea ice (Figure 3). By April 2017, ice in western HB (moorings AN01 and NE03) was thicker than the FDD estimate, whereas in southeastern HB (mooring JB02) the ice was thinner than the FDD estimate (Figure 3). The opposite pattern was observed in April 2018: thinner ice measured at west and thicker in the southeast.

The primary modes of measured ice thickness distributions in April 2017 and 2018 (Figure 3, right panels) demonstrate this pattern in more detail. The modal ice thicknesses in western HB between April 2017 and April 2018 decreased from $1.27 \mathrm{~m}$ (AN01) and $1.29 \mathrm{~m}$ (NE03) to 0.71 and $0.87 \mathrm{~m}$, respectively. Meanwhile, in southeastern HB, modal thickness in April increased from $0.91 \mathrm{~m}$ in 2017 to $1.29 \mathrm{~m}$ in 2018. Although the 2018 ice season was longer and colder, the difference in the empirical ice thickness calculated from FDD at each mooring site was only 0.10 to $0.15 \mathrm{~m}$ (Figure 3), suggesting a dynamic origin for a majority of the observed anomalies rather than interannual differences in the rates of thermodynamic growth. The 

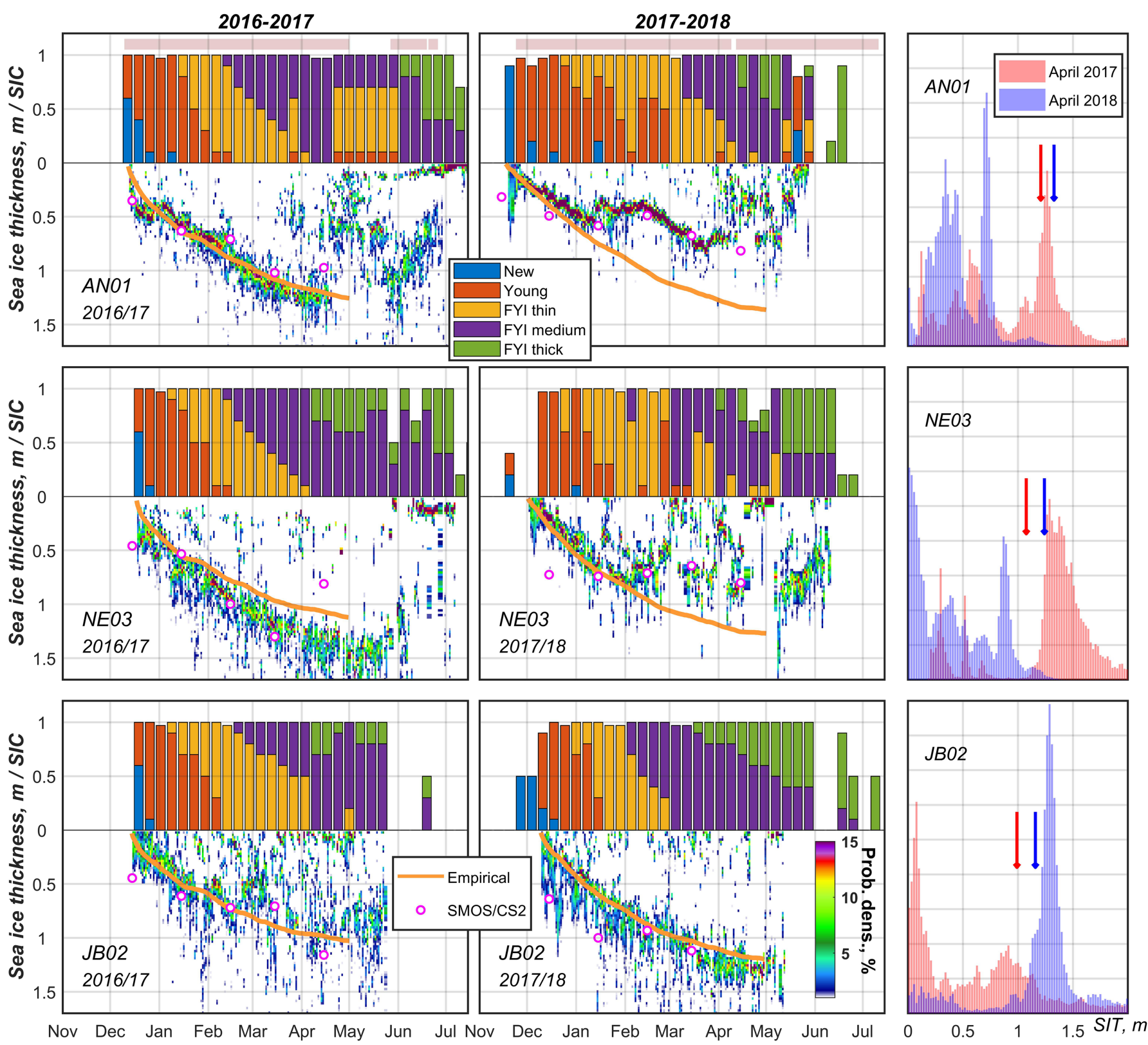

Figure 3. Evolution of SITs and ice types at AN01 (top), NE03 (middle), and JB02 (bottom) during winter 2017 and 2018. The measured SITs are shown as a percent occurrence, and those maxima (from green to red colors) correspond to the peak probability of daily SIT at 2-cm bin spacing. The monthly mean CS2/SMOS data are presented as magenta circles at the center of every month. Daily mean SIT estimated from empirical thermodynamic growth is shown with orange line. CIS data on partial concentration of different types of sea ice are shown with color bars (new $<10 \mathrm{~cm}$, young $<10-30 \mathrm{~cm}$, FYI thin 30-70 cm, FYI medium 70-120 cm, and FYI thick $>120 \mathrm{~cm}$ ). Availability of OSI-405-c ice drift data is shown with pink horizontal bars at the top of the figure. The normalized frequency distributions of measured SIT at 2-cm bin spacing in April 2017 and 2018 are shown in the right panels together with arrows indicating the April-averaged empirical SITs.

spatial asymmetry is also evident in the thin ice portion of the ice thickness distributions that is associated with relatively thin ice formed in the coastal polynyas. This secondary mode related to the thin ice is specifically pronounced at NE03 in April 2018 (Figure 3, right panels).

Despite representing single-point data, the temporal evolution of measured SITs at each mooring is consistent with the seasonal and regional change of ice types presented by CIS ice charts. A relatively steady ice growth observed at AN01 and NE03 during winter 2017 and at JB02 in 2018 is evident in CIS data as a gradual decrease of young ice fraction and increased presence of thicker ice types (Figure 3). Intrusions of thin 

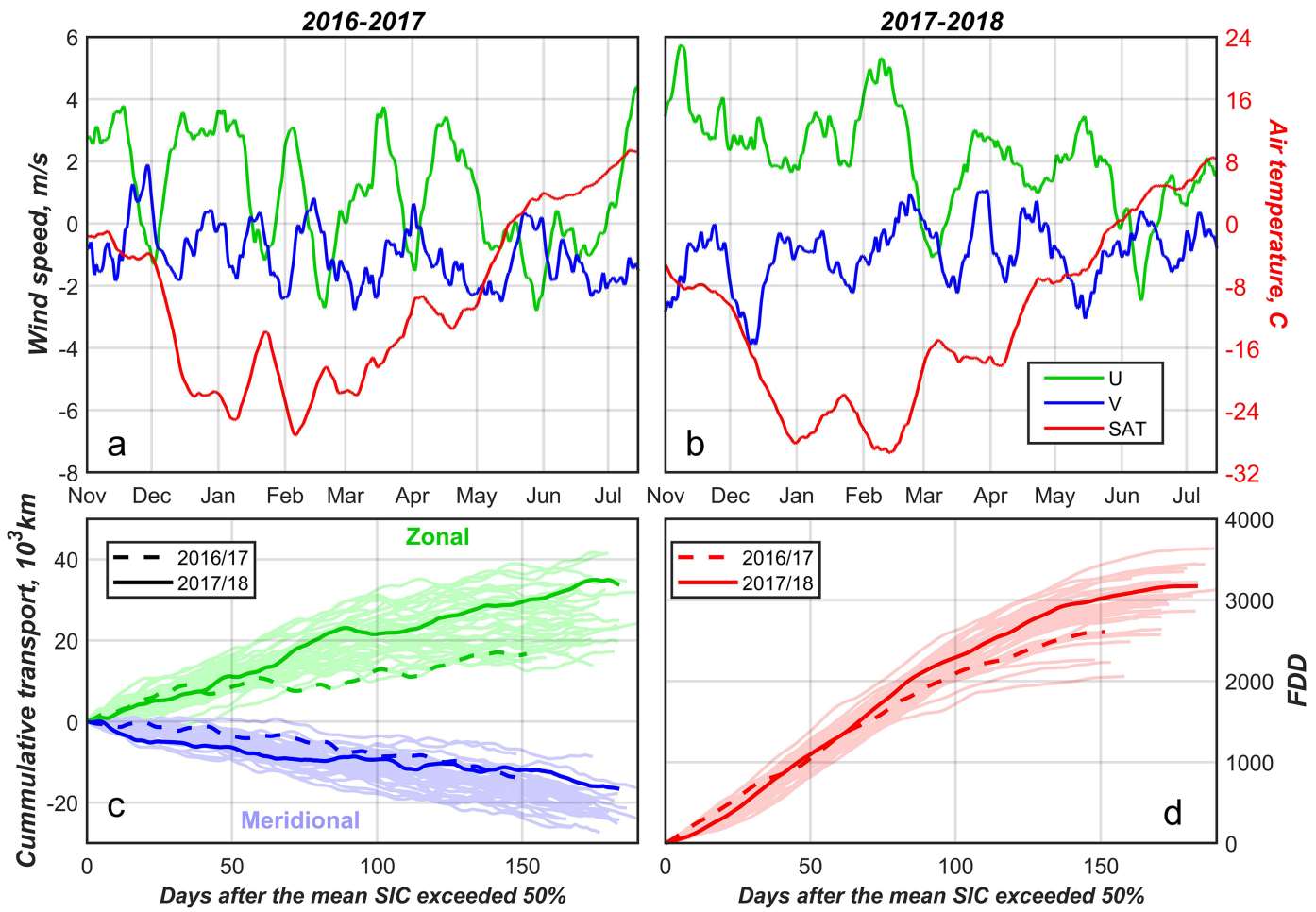

Figure 4. (a and b) Two-week-averaged zonal $(U)$ and meridional $(V)$ wind speed and SAT averaged over central Hudson Bay $\left(78-95^{\circ} \mathrm{W}, 55-63^{\circ} \mathrm{N}\right)$, (c) cumulative zonal and meridional air transport, and (d) FDD during ice growth season. The historical 1978-2016 FDD data are shown in background.

ice observed at AN01 and NE03 in the middle of winter 2018 are the result of new ice forming and circulating south from the northwest HB coastal polynya.

The spatial asymmetry in SIT between the two years observed from the mooring data is also found at the basin-wide scale (Figure 1a) and highlights two key areas where the ice cover varied between the two years. In southern HB (southern domain - blue box), the ice cover was $0.46 \mathrm{~m}$ thinner in April 2018 than it was in 2017 ( $0.88 \mathrm{~m}$ vs. $1.34 \mathrm{~m}$ ), whereas in eastern HB (eastern domain - red box) the ice cover was $0.48 \mathrm{~m}$ thicker in April 2018 than it was in 2017 (1.32 m vs. $0.84 \mathrm{~m}$ ). SIT during both 2017 and 2018 was thinner than the 2003-2016 April means presented by Landy et al. (2017) for similar geographic regions, though the negative anomaly was greatest in the southern domain in $2018(0.88 \mathrm{~m}$ vs. $1.44 \mathrm{~m})$ and in the eastern domain in 2017 $(0.84 \mathrm{~m}$ vs. $1.67 \mathrm{~m})$. Moreover, the common zonal SIT gradient identified by Landy et al. (2017) was present in 2018 but was inverted in 2017.

\subsection{Dynamic Versus Thermodynamic Factors Controlling the Asymmetry in SIT}

The distinct difference between empirical thermodynamic ice growth and measurements in Figure 3 implies that dynamic thickening may play an important role in the zonal asymmetry of SIT of HB. Based on the

Table 1

Characteristics of 2017 and 2018 Sea Ice Seasons in Hudson Bay

\begin{tabular}{lll}
\hline & \multicolumn{1}{c}{ Winter 2016-2017 } & Winter 2017-2018 \\
\hline Date of freeze-up & 15 December 2016 (late) & 30 November 2017 (early) \\
Date of breakup & 19 May 2017 (early) & June 2018 (late) \\
Duration of ice season & 22 weeks (short) & weeks (long) \\
Wind & NNW, weak & WNW, strong \\
Type of atmospheric forcing (wind/SAT) & South/warm (Type IV) & East/cold (Type I) \\
Ice motion & Cyclonic, weak & Cyclonic, strong \\
Ice thickness anomalies at the end of winter (in April) & Thick in west/south thin in east & Thin in west/south thick in east \\
\hline
\end{tabular}



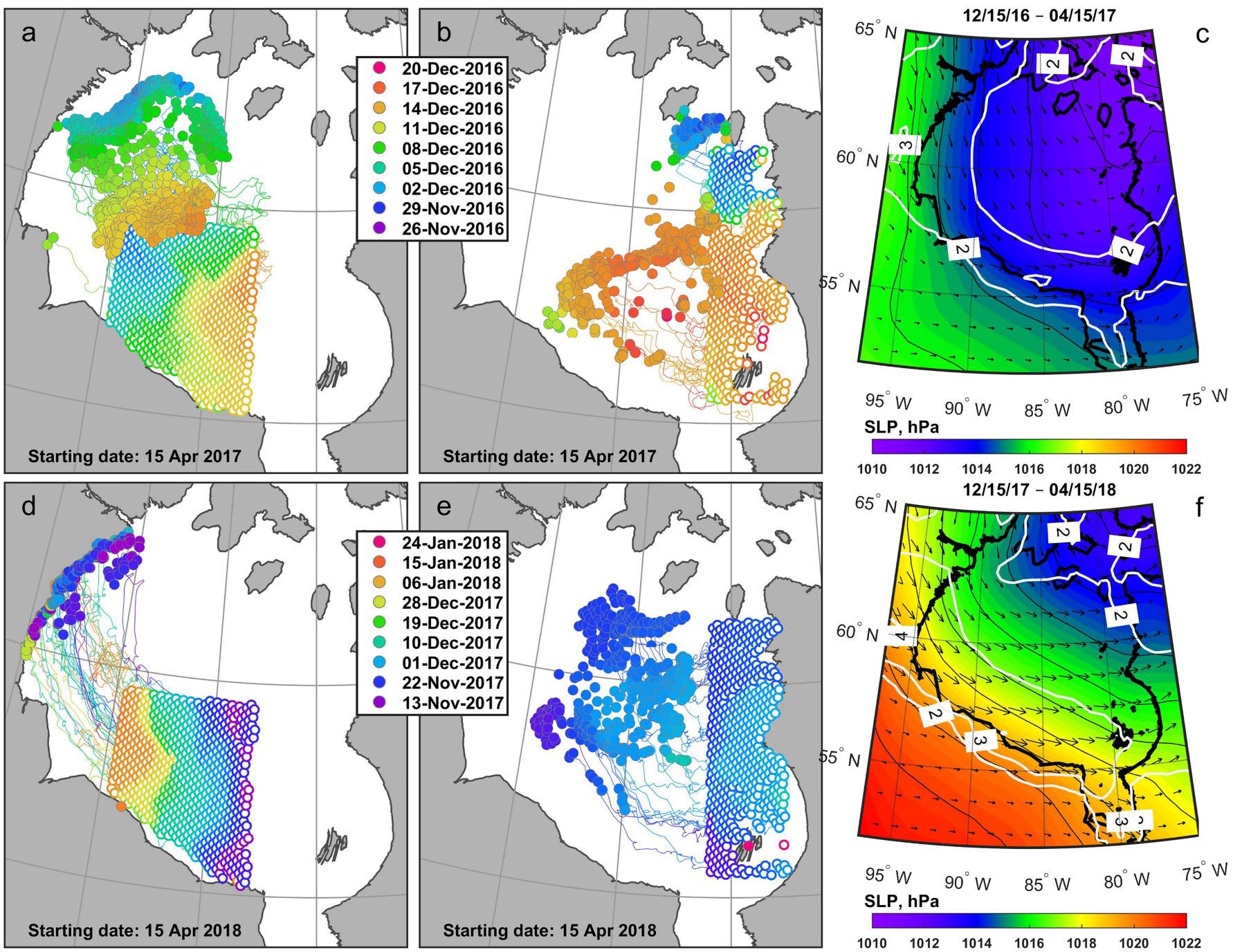

Figure 5. The back trajectories of sea ice drift from the southern (a,d) and eastern (b, e) domains in 2017 (a, b) and 2018 (d, e). Open circles denote the position of the ice on 15 April, while the filled circles indicate positions of first appearance of sea ice (SIC > 15\%) with colors showing the date of ice formation.

The paired positions only are shown. (c, f) Mean sea level pressure and surface winds between 15 December and 15 April in 2016/2017 and 2017/2018, respectively. Selective isotachs $(\mathrm{m} / \mathrm{s})$ are presented with labeled white lines.

National Snow and Ice Data Center 25-km Polar Pathfinder sea ice motion vectors, Landy et al. (2017) reported that west-to-east increase in SIT could be attributed to generally cyclonic ice motion in the HB and dynamic convergence against the eastern coast. To corroborate the dynamic origin of observed east-west asymmetry of SIT in 2017 versus 2018, parcels of ice are projected through daily OSI SAF fields of ice drift from an arbitrary transect in northwest HB from the onset of ice formation in 2016 and 2017 (Figures 1b and 1c). Ice drift was faster during winter 2018 (vectors in Figure 1) and as a result by the end of April the ice front was located 100-200 km east of its position in April 2017. This gap increased to $300 \mathrm{~km}$ in the two following months due to a reversal and westward drift in May-June 2017.

The mean ice drift patterns clearly demonstrate stronger cyclonic eastward ice circulation in 2018 compared to 2017 when the southward component of ice drift was more pronounced (Figures $1 \mathrm{~b}$ and $1 \mathrm{c}$ ). The variation in ice drift between the two years has implications for the convergence and dynamic deformation of the ice cover and also determines the source region of sea ice in HB. Calculating the back trajectories of ice drift from the southern and eastern domains from 15 April to the day of ice formation highlights how the two years of 2017 and 2018 differed. In terms of the southern domain, in 2017 the source region was a large area in northwestern and central HB (Figure 5a), whereas the source region in 2018 was associated with a 

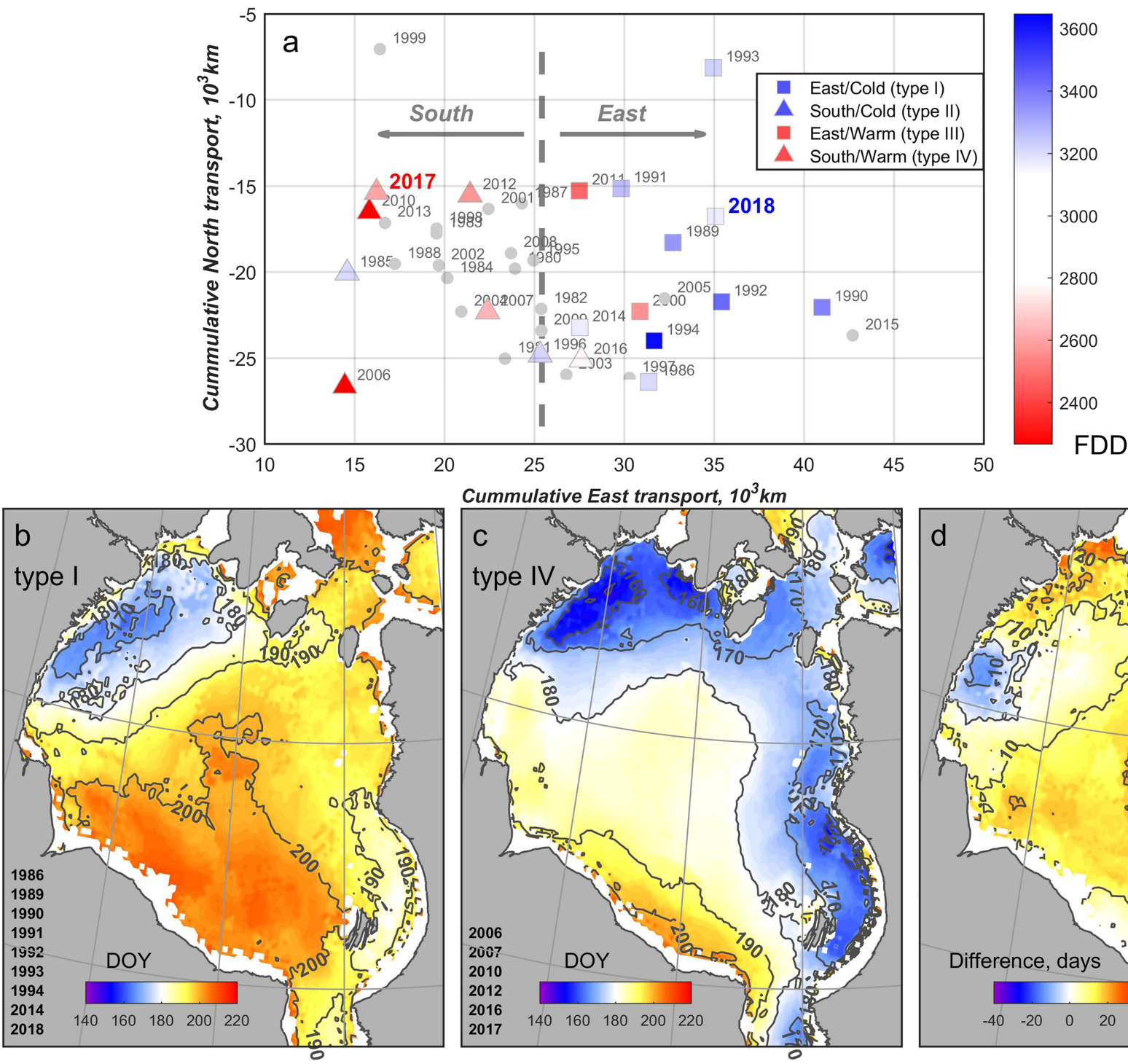

Cummulative East transport, $10^{3} \mathrm{~km}$
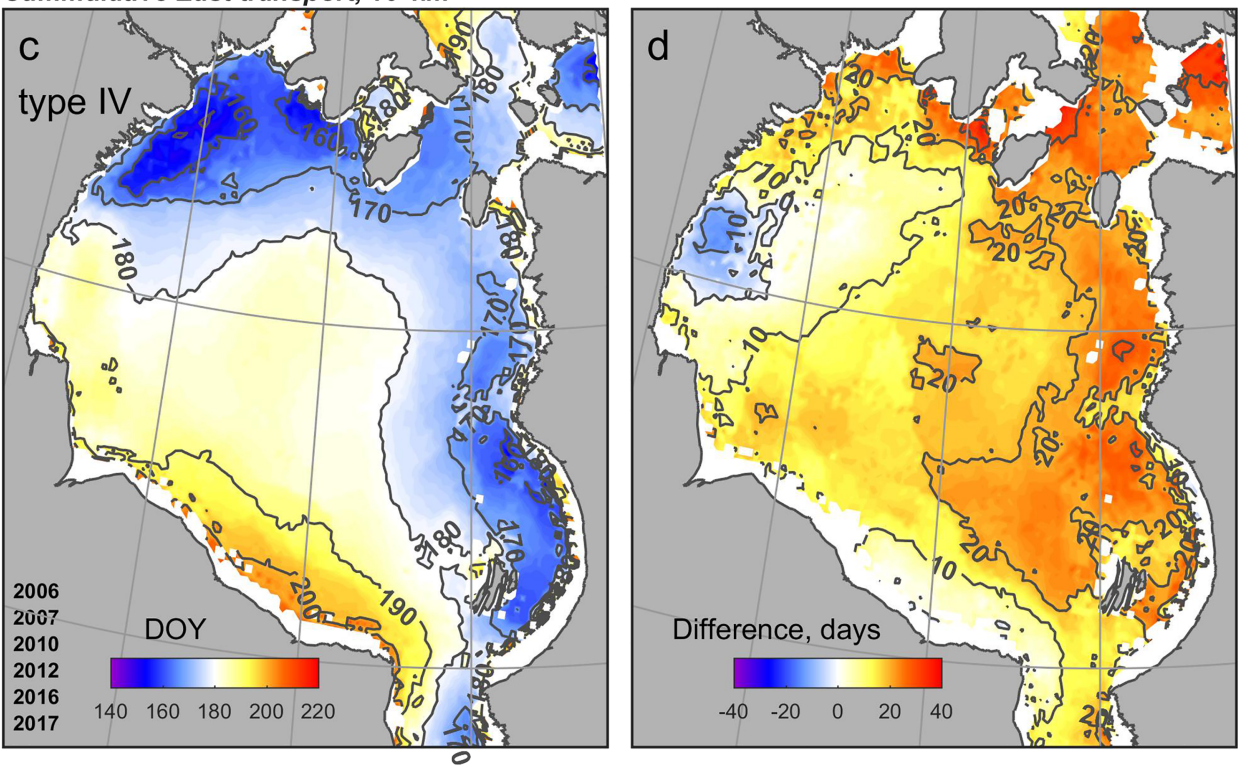

Figure 6. (a) The cumulative components of wind transport over central HB during winters 1979-2018. Colored squares and triangles represent the intensity of eastern transport relative to the climatic mean (i.e., squares correspond to stronger westerly winds). Gray dots indicate the years when FDD was within $\pm 0.5 \sigma$, that is, not corresponding to any of the four types. The colors indicate the FDD above and below one standard deviation from the climatic mean. (b, c) The multiyear-averaged ice retreat dates (DOY) associated with Types I and IV of atmospheric forcing and (d) corresponds to their difference.

relatively narrow zone along the northwestern coast (Figure 5d), associated with the recurrent coastal polynya. The first appearance of ice was also different for these two areas with dates changing from 1-15 December in 2016 to 15 November to 15 January in 2017/2018. Despite significant temporal variability in freeze-up timing, the interannual variation of empirical thermodynamic SIT in the southern domain by the middle of April does not exceed $0.15 \mathrm{~m}$. This implies that the observed difference of $0.46 \mathrm{~m}$ in SIT in the southern domain is likely explained by stronger divergence of sea ice in 2018 compared to convergence in 2017. Similar analysis conducted for the eastern domain also reveals small interannual variations in empirical thermodynamic SIT $(<0.15 \mathrm{~m})$. This suggests that the $0.48-\mathrm{m}$ thinner ice in April 2017 can be explained by reduced convergence along the eastern coast (Figures $5 \mathrm{~b}$ and 5e). The atmospheric circulation corroborates the dynamical origin of the observed SIT anomalies. Thus, winter 2017 is characterized by low SLP over the central HB and relatively weak NNW winds (Figure 5c) with numerous reversals (Figure 4). Conversely, winter 2018 is characterized by a high SLP gradient across HB that leads to approximately 2 times stronger WNW winds and enhanced zonal ice transport (Figure 5f). Comparison of SLP and wind regimes in 2017 and 2018 on regional scales shows that the former is 

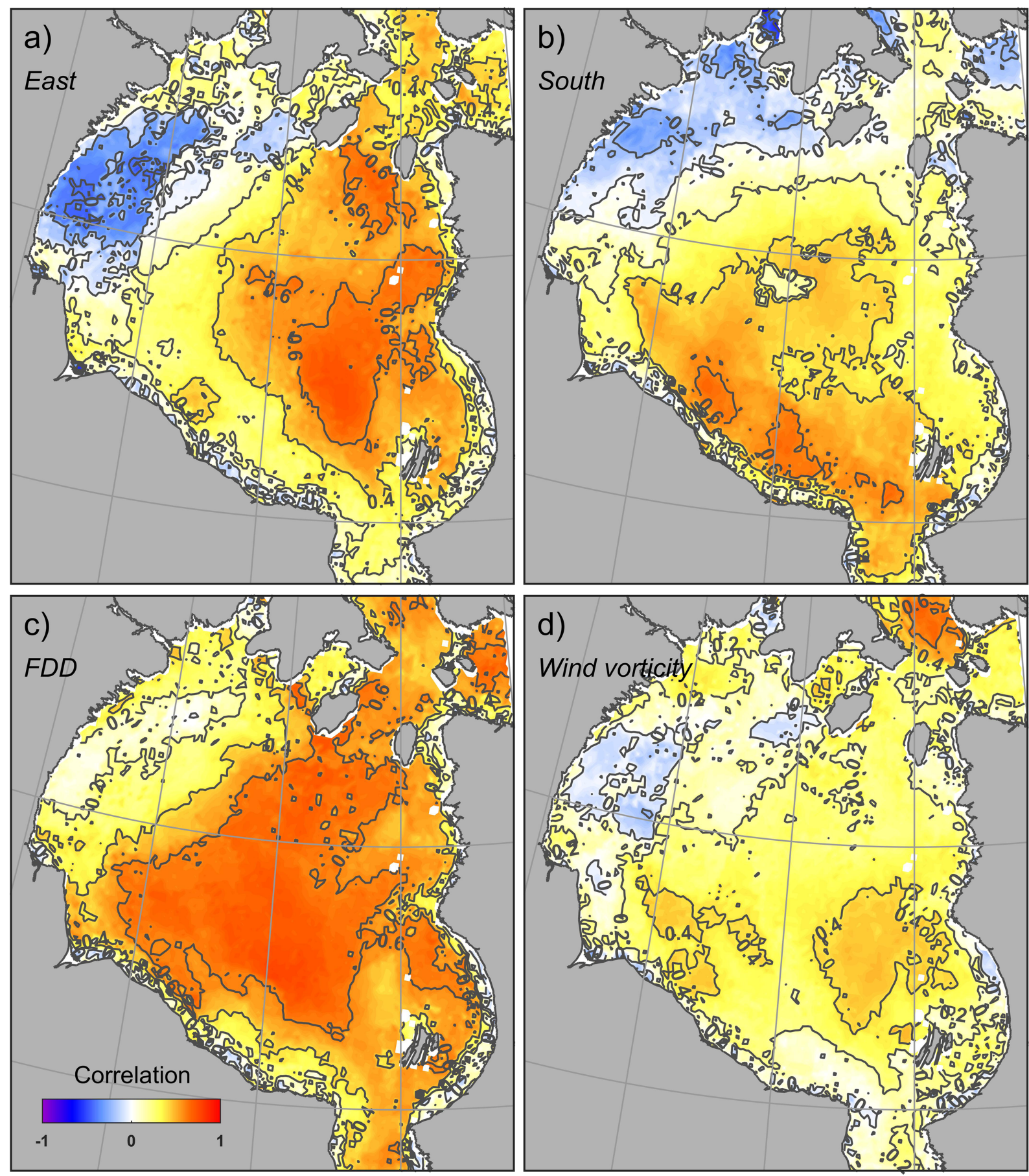

Figure 7. Spatial distribution of linear correlation between DOY of breakup dates (SIC < 15\%) and (a, b) cumulative zonal (east) and meridional (south) air transports, (c) freezing-degree days, and (d) wind vorticity during winter (considered as the period when SIC and surface air temperature over central Hudson Bay $\left(78-95^{\circ} \mathrm{W}, 55-63^{\circ} \mathrm{N}\right)$ were greater than $50 \%$ and below $0{ }^{\circ} \mathrm{C}$, respectively).

characterized by predominantly meridional transport that contributes to sea ice accumulation in southern $\mathrm{HB}$, in contrast to zonal transport observed in 2018 that contributes to accumulation of sea ice in eastern HB.

\subsection{The Impact of Atmospheric Forcing During Ice-Growth Season on Breakup Timing}

To place the atmospheric forcing during winters 2017 and 2018 in the context of the mean climate state and to link it to the timing of ice breakup, the mean cumulative surface wind transport and FDD over the central 
$\mathrm{HB}\left(78-95^{\circ} \mathrm{W}, 55-63^{\circ} \mathrm{N}\right)$ are calculated for each ice growth season since 1979 . The cumulative wind transport is used instead of mean zonal and meridional wind speed to account for the interannual variability of ice growth season length. Using $\pm 0.5 \sigma$ for FDD and the mean 1979-2018 zonal wind transport as thresholds, we decompose four types of atmospheric forcing that correspond to warm or cold winters and strong or weak eastward wind transport (Figure 6a). For the 40-year record, Types I (east/cold) and IV (south/warm) were the most common, occurring nine and six times, respectively. Type I was most commonly observed in the late 1980s to early 1990s, though 2018 was classified as Type I, whereas Type IV has occurred more frequently over the last decade and characterized 2017. The other two types-south/cold and east/warmoccurred only three and two times, respectively, because of a relatively high correlation $(+0.53)$ between the zonal wind transport and FDD. Note that south and east are used as relative terms here, rather linked to two geographical domains than to the real wind transport direction varying climatically from SSE to ESE.

The impact that the two major types (I and IV) have on spring breakup of the ice cover is quite considerable. Type I is characterize by the classic northwest to southeast evolution of breakup (Figure 6b), whereas Type IV has a zonal asymmetry with breakup occurring in eastern HB simultaneously to breakup in northwestern HB (Figure 6c). On average, breakup occurs 20 days later during cooler Type I years compared to warmer Type IV years, which have mostly been observed during the last decade. Between Types I and IV years, the ice breakup date varies on average by 10 days in western and southern regions of HB but can vary by up to 30 days in the eastern region (Figure 6d). The breakup timing differences for individual years can exceed these mean estimates. For instance, the ice persisted for more than 40 days longer in the east and for 20 days shorter in the west in 2018 (Type I) compared to 2017 (Type IV). This is confirmed by visible MODIS images showing sea ice remaining in HB until at least 29 June 2017 but almost one month later the following year until 22 July 2018 (Figures $1 \mathrm{~b}$ and 1c).

Our results corroborate the strong impact of atmospheric forcing on the zonal anomalies of SIC reported by Hochheim et al. (2011). However, Hochheim et al. (2011) restricted their analysis to the forcing during spring (April-June) and did not account for the end of winter ice thickness fields as the data were unavailable at the time. In our study, we focus on atmospheric forcing during the entire winter to demonstrate the relation between summer breakup and the interannual variability of dynamic and thermodynamic ice growth. The tight bound between the individual components of atmospheric forcing and breakup timing is also evident in Figure 7 showing the spatial distribution of partial correlations. Not surprisingly, strong western/northern winds during winter lead to presumably stronger convergence and dynamic ice growth along eastern/southern coasts. As a result, ice generally persists in these areas for longer into summer and presents hazardous conditions for shipping vessels attempting to transit through the area or access coastal communities. Breakup timing is also positively correlated with FDD over the entire HB, although the largest correlations are observed in the central portion of HB (Figure 7). The positive, though relatively weak, correlation between breakup dates and wind vorticity (Figure 7d) is consistent with reduced summer sea ice extent documented by Hochheim et al. (2011) during what is characterized as a negative ice vorticity regime (with ice drift and atmospheric conditions similar to the 2017 conditions and Type IV classification used in the present study).

\section{Conclusions}

The timing of sea ice freeze-up and breakup within HB demonstrated substantial differences between the sea ice seasons of 2016/2017 and 2017/2018. As is typical of the region, freeze-up progressed from northwest to southeast during both years, though it occurred on average 2 weeks later in fall 2016 compared to 2017. In terms of breakup, it occurred on average 3 weeks earlier during 2017 compared to 2018, but the key difference was the breakup pattern and the location of the remnant sea ice. In 2017 remnant ice was located in south-southwestern HB until 10-15 July, whereas remnant ice in 2018 was located in eastern HB until 25-30 July and created hazardous conditions that delayed the start of the summer shipping season.

While breakup reflects forcing by various dynamic and thermodynamic processes, the state of the end of winter ice cover has an important role in the procession of ice breakup. Using a combination of in situ and remotely sensed observations of SIT, we highlight differences in the zonal asymmetry of ice thickness between the two winters of 2017 and 2018 that influenced the pattern of breakup. In situ observations show that the modal ice thickness at the end of winter 2017 was $0.36-0.38 \mathrm{~m}$ thicker in the west and $0.42-0.58 \mathrm{~m}$ 
thinner in the southeast compared to 2018, which is considerably greater than the difference of $\sim 0.10-0.15 \mathrm{~m}$ estimated from FDD between years. This highlights the role of dynamics in driving the zonal asymmetry of SIT across HB. On a broader bay-wide scale, remotely sensed fields of SIT confirm the difference in zonal asymmetry between the two years. On average SIT was $0.48 \mathrm{~m}$ thinner in eastern HB in April 2017 and $0.46 \mathrm{~m}$ thinner in southern HB in April 2018. Based on remotely sensed fields of ice drift, we determine that lower SITs within the eastern domain in 2017 (0.83 m below the 2003-2016 climatology) can be, at least partly, attributed to lower convergence associated with much weaker NNW winds that reduced the cyclonic drift pattern during winter 2017 compared to the climatological drift fields and the winter of 2018. Moreover, in 2017 the reduction in eastward winds precluded convergence of the ice cover in eastern HB, creating negative ice thickness anomalies that exhibit an inversion of the west-east climatological SIT gradient identified by Landy et al. (2017). Conversely, in 2018 strong WNW winds increased cyclonic ice drift speeds and led to convergence and thus formation of thicker ice in eastern HB (0.56 m above the 2003-2016 climatology), while divergence in western HB created a thinner ice cover in the area of the northwestern polynya.

Based on the contribution of dynamic and thermodynamic factors to ice growth and resultant patterns of breakup during the two winters of 2017 and 2018, we extend our analysis to the historical sea ice record. From atmospheric reanalysis we used the cumulative wind speed and air temperature over central HB during winter to classify atmospheric forcing into four different classes based on either warm/cold air temperatures and strong/weak eastward wind transport. While half of all winters were confined within 0.5 standard deviation of the 1979-2018 mean FDD, the two most frequent types, east/cold (Type I) and south/warm (Type IV)—are found to considerably impact the zonal asymmetry of the breakup pattern and were representative of winter 2018 and 2017, respectively. The lower air temperatures and stronger eastward sea ice transport that lead to convergence along the eastern coast, characteristic of Type I, delay breakup by approximately 1 month across the Bay compared to the warmer Type IV, which is characterized by weaker dynamic ice growth in the east. Between these two types, the difference in breakup is low in the western and southern shores and greatest in eastern HB. This difference is particularly important for the open-water shipping season as delayed breakup in eastern HB creates hazardous conditions for vessels, which require icebreaker escorts and delay resupply shipment to the isolated communities. The winters with strong eastward wind components consequently led to delayed resupply shipments and the need for icebreaker escorts in 2015 and 2018. Our results link the winter atmospheric forcing regime to the spatial pattern in ice thickness that in turn influences the breakup pattern and offers a potential relationship for seasonal forecasting of breakup patterns. Additionally, our findings help to distinguish the thermodynamic and dynamic drivers of SIT and highlight the importance of dynamics in dictating the physical properties of the HB ice cover.

Acknowledgments
This work is a contribution to the Natural Sciences and Engineering Council of Canada (NSERC)

Collaborative Research and Development project: BaySys (CRDPJ 470028-14). Funding for this work, including field studies, was provided by NSERC, Manitoba Hydro, the Canada Excellence Research Chair (CERC) program, and the Canada Research Chairs (CRC) program. Authors acknowledge the Ocean and Sea Ice Satellite Application Facility for their sea ice concentration and ice motion products (http://www.osi-saf.org/?q= content/sea-ice-products) and the European Centre for Medium-Range Weather Forecasts for the ERA-Interim wind, air temperature, and pressure data (https://www.ecmwf.int/en/forecasts/datasets/reanalysis-datasets/erainterim). The authors also thank the European Space Agency for Cryosat-2 ice thickness data (https://science-pds. cryosat.esa.int/). This work is a contribution to the Arctic Science Partnership (ASP) and ArcticNet. The ADCP data used in research are available through the Polar Data Catalogue at https:// www.polardata.ca (CCIN Reference 13105).

\section{References}

Andrews, J., Babb, D., \& Barber, D. G. (2018). Climate change and sea ice: Shipping in Hudson Bay, Hudson Strait, and Foxe Basin (19802016). Elementa: Science of the Anthropocene, 6, 19. https://doi.org/10.1525/elementa.281

Andrews, J. A., Babb, D. G., McKernan, M., Horton, B., \& Barber, D. G. (2016). Climate change in the Hudson Bay Complex: Opportunities and vulnerabilities for the Port of Churchill's Marine Operations. Centre for Earth Observation Science, 130. https://doi.org/10.5203/ lwbin.ceos.2016.1

Babb, D. G., Andrews, J., Dawson, J., Mussells, O., \& Weber, M. (2019). Marine transportation. In Z. Z. Kuzyk, \& L. M. Candlish (Eds.), From science to policy in the Greater Hudson Bay Marine Region: An Integrated Regional Impact Study (IRIS) of climate change and modernization (pp. 341-377). Quebec City: ArcticNet.

Cavalieri, D. J., \& Parkinson, C. L. (2012). Arctic sea ice variability and trends, 1979-2010. The Cryosphere, 6, 881-889. https://doi.org/ $10.5194 /$ tc-6-881-2012

Danielson, E. W. (1971). Hudson Bay ice conditions. Arctic, 24(2), 90-107.

Dee, D. P., Uppala, S. M., Simmons, A. J., Berrisford, P., Poli, P., Kobayashi, S., et al. (2011). The ERA-Interim reanalysis: Configuration and performance of the data assimilation system. Quarterly Journal of the Royal Meteorological Society, 137(656), 553-597. https://doi.org/ $10.1002 /$ qj. 828

Fequet, D. (Ed) (2005). Manual of standard procedures for observing and reporting ice conditions, (9th ed.). Canada, Ottawa: Can. Ice Serv., Environ.

Gagnon, A. S., \& Gough, W. A. (2005). Trends in the dates of ice freeze-up and breakup over Hudson Bay, Canada. Arctic, 58(4), $370-382$. Gagnon, A. S., \& Gough, W. A. (2006). East-west asymmetry in long-term trends of landfast ice thickness in the Hudson Bay region, Canada. Climate Research, 32, 177-186.

Galbraith, P. S., \& Larouche, P. (2011). Sea-surface temperature in Hudson Bay and Hudson Strait in relation to air temperature and ice cover breakup, 1985-2009. Journal of Marine Systems, 87(3), 463-475. https://doi.org/10.1016/j.jmarsys.2011.06.006

Gough, W. A., Gagnon, A. S., \& Lau, H. P. (2004). Interannual variability of Hudson Bay ice thickness. Polar Geography, 28(3), $222-238$. Gunn, G. (2014). Polynya formation in Hudson Bay during the winter period. Thesis, University of Manitoba, Winnipeg, Canada.

Hochheim, H. P., Lukovich, J. V., \& Barber, D. G. (2011). Atmospheric forcing of sea ice in Hudson Bay during the spring period, 19802005. Journal of Marine Systems, 88, 476-487. 
Hochheim, K. P., \& Barber, D. G. (2010). Atmospheric forcing of sea ice in Hudson Bay during the fall period, 1980-2005. Journal of Geophysical Research, 115, C05009. https://doi.org/10.1029/2009JC005334

Hochheim, K. P., \& Barber, D. G. (2014). An update on the ice climatology of the Hudson Bay System. Arctic, Antarctic, and Alpine Research, 46(1), 66-83. https://doi.org/10.1657/1938-4246-46.1.66

Kowal, S., Gough, W. A., \& Butler, K. (2017). Temporal evolution of Hudson Bay Sea Ice (1971-2011). Theoretical and Applied Climatology, 127(3-4), 753-760. https://doi.org/10.1007/s00704-015-1666-9

Krishfield, R. A., Proshutinsky, A., Tateyama, K., Williams, W. J., Carmack, E. C., McLaughlin, F. A., \& Timmermans, M.-L. (2014) Deterioration of perennial sea ice in the Beaufort Gyre from 2003 to 2012 and its impact on the oceanic freshwater cycle. Journal of Geophysical Research, Oceans, 119, 1271-1305. https://doi.org/10.1002/2013JC008999

Landy, J. C., Ehn, J. K., Babb, D. G., Thériault, N., \& Barber, D. G. (2017). Sea ice thickness in the Eastern Canadian Arctic: Hudson Bay Complex \& Baffin Bay. Remote Sensing of Environment, 200, 281-294. https://doi.org/10.1016/j.rse.2017.08.019

Lavergne, T., Eastwood, S., Teffah, Z., Schyberg, H., \& Breivik, L. A. (2010). Sea ice motion from low resolution satellite sensors: An alternative method and its validation in the Arctic. Journal of Geophysical Research, 115, C10032. https://doi.org/10.1029/2009JC005958

Lebedev, V. V. (1938). Ice growth in the Arctic rivers and seas and its dependence on negative air temperatures. Arctic Proceedings, 5-6(p), 9-25.

Markham, W. E. (1981). Ice atlas of Canadian arctic waterways, (p. 198). Toronto: Environment Canada Atmospheric Environment Service. Ogi, M., Barber, D. G., \& Rysgaard, S. (2016). The relationship between summer sea ice extent in Hudson Bay and the Arctic Ocean via the atmospheric circulation. Atmospheric Science Letters, 17(11), 603-609. https://doi.org/10.1002/asl.709

Prinsenberg, S. J. (1988). Ice-cover and ice-ridge contributions to the freshwater contents of Hudson Bay and Foxe Basin. Arctic, 41(1), 6-11.

Saucier, F. J., Senneville, S., Prinsenberg, S., Roy, F., Smith, G., Gachon, P., et al. (2004). Modelling the sea ice-ocean seasonal cycle in Hudson Bay, Foxe Basin and Hudson Strait, Canada. Climate Dynamics, 23, 202-326.

Stroeve, J. C., Markus, T., Boisvert, L., Miller, J., \& Barrett, A. (2014). Changes in Arctic melt season and implications for sea ice loss. Geophysical Research Letters, 41, 1216-1225. https://doi.org/10.1002/2013GL058951

Tivy, A., Howell, S. E., Alt, B., McCourt, S., Chagnon, R., Crocker, G., et al. (2011). Trends and variability in summer sea ice cover in the Canadian Arctic based on the Canadian Ice Service Digital Archive, 1960-2008 and 1968-2008. Journal of Geophysical Research, 116, C03007. https://doi.org/10.1029/2009JC005855 